\title{
Plants used as antidotes against bites of venomous animals in Mizoram, Northeast India
}

\author{
S. D. Khomdram ${ }^{2}$, S. D. Yumkham ${ }^{1}$ and V. L. Malsawmi Colney \\ Department of Botany, Mizoram University, Aizawl-796004, Mizoram, India \\ ${ }^{1}$ Ethnobotany \& Plant Physiology Laboratory, Centre of Advanced Studies in Life Sciences, Manipur \\ University, Canchipur- 795003, Manipur, India \\ ${ }^{2}$ Corresponding author, E-mail: sandhyakhomdram@gmail.com
}

[Received 15.11.2018; Revised 04.12.2018; Accepted 17.12.2018; Published 31.12.2018]

\begin{abstract}
The rich traditional knowledge on the use of plants as antidotes against various types of venomous animals like hymenopteran insects, spiders, scorpions, leech and snakes found in Mizoram is highlighted in the present study. The study was conducted through the collection of data from 50 local informants using semi-structured questionnaire. A total of 23 species from 17 families is documented with their botanical name, family, local name, voucher number, habit and local distribution, part/s used and their mode of uses. This study indicates the importance of plant resources as an effective source of antidotes which are commonly used during the time of emergency by the indigenous people of Mizoram. Such knowledge inherited from the ancestors through generations needs to be documented and experimented for the use and benefit of people at large.
\end{abstract}

Key words: Traditional knowledge, Antidotes, Animal bites, Mizoram

\section{INTRODUCTION}

Venomous animals are the ones that can produce substance whose pharmacological activity can potentially interfere with the survival of humans. They developed tools of specific accessories like fangs, hairs, spines, tentacles or others for inoculation of venom to capture the preys or to defend themselves from predators. The venoms produced by these animals are not necessarily dangerous to humans, however, they naturally have a deleterious effect on humans. Animal bites or stings are usually used interchangeably to describe the mode of venom or poison injection to humans (Vetter \& Visscher 1998; Espino-Solis 2009). An antidote is a substance which can counteract the poison or venom produced by animals or insects. Although antidotes, or sometimes referred as antivenins are available against venomous animals like snakes, hymenopteran insects (bees, hornets, and wasps), scorpions and spiders, it cannot be available at the time of emergency at remote areas with no proper transport infrastructures. So, indigenous people living in remote areas have to depend on the traditional knowledge developed around the specific conditions of women and men indigenous to the particular area (Mahalik \& Mahapatra 2010).

Since time immemorial, plants and human beings have close relationships due to parallel evolution for their existence and their interdependence among each other (Shil et al., 2014). In the line of evolution, plants provide the nutritional and healthcare needs that include the use of plants as antidotes against different kinds of insect bites, scorpion bites and even snake bites. The result of close association of humans with its immediate environment lead to the development of the indigenous knowledge including the plant use associated with 
specific regions of the world that are confined to that area. The indigenous people are generally aware of their surrounding biodiversity and understand the link between the traditional uses of plant in ethnomedicine for curing various ailments. Few works with scattered information related to the use of plants as antidotes against venomous animal bites were available (Lalfakzuala et al. 2007; Rai \& Lalramnghinglova 2010), but no detailed study related to the present study in Mizoram is found. So, the study was initiated to identify some of the commonly used plants as antidotes against venomous animals like insects (mostly hymenopterans), scorpions, spiders and snakes in Mizoram as frequent occurrence of such incidence is reported from the state as major part of the region is represented by hilly areas.

\section{MATERIALS AND METHODS}

\section{A. Study area and People}

Mizoram is a hilly state of Northeast (NE) India and is part of the Indo-Burma biodiversity hotspots of the world. It is a landlocked state that shared its boundary with international countries of Myanmar and Bangladesh. The inhabitants of the state are dominated by diverse ethnic tribal communities like Lusei (Mizo), Pawis, Paites, Raltes, Pangs, Hmars etc. and represents the highest percentage of tribal population among all the states in India (Ali \& Das 2003). Among the various tribal groups, the Mizo community dominated most part of the state. The state is also having the largest percentage of forest area $(86.27 \%)$ among all the Indian states and union territories (FSI 2017). Due to its mountainous topography, there is less accessibility to various parts of the state and major portion of the state is still found to be rural and under developed. So, most of the indigenous people of the state have to depend on the available natural resources especially plants as remedies at the time of emergencies due to their rich traditional knowledge gain through generations as well as lack of adequate primary health facilities.

\section{B. Survey and Plant Identification}

A total of 50 informants were interviewed during an intensive survey program during March 2016 to June 2018 from 5 selected villages of Aizawl district, namely Hmuifang, Sairang, Sialsuk, Tanhril and Tuirial. The data was collected through face to face interview based on semi structured questionnaire with prior, free informed consent from each informant with the target informants representing both male and female of different age groups including the traditional healers from 40 years and above. The plant specimens mentioned by the informants were also collected and made into herbarium specimens following Jain \& Rao (1977) methods. These collected plants were identified through consulting the floras and available literatures (Gage 1901; Fischer 1938; Deb \& Dutta 1987; Sinha et al. 2002, 2012; Sawmliana 2013). The voucher specimens prepared were deposited in the herbarium of Department of Botany (MZUH), Mizoram University.

\section{RESULTS AND DISCUSSION}

Among the total number of 50 informants, 33 representing 66\% were male and the remaining 17 informants representing $44 \%$ were the females. Considering the age group of the informants, maximum percentage of informants $(40 \%)$ were represented from the age group older than 65 years followed by $38 \%$ with the age group between 56 to 65 years and $22 \%$ for the age group between 40 to 55 years highlighting more knowledge on the present study by elder informants as compare to younger ones.

A total of 23 species under 17 families are commonly used in Mizoram as antidotes against different kinds of animal bites that include insect bites, scorpion bites, spider bites and 
even snake bites. Also, plants used against wounds and sores made by leeches are also mentioned although leeches are not truly venomous. Among the plant families, maximum number of species is reported from Fabaceae and Zingiberaceae families representing 3 species each followed by Asteraceae and Lamiaceae with 2 species and the remaining families represented by 1 species each (Figure 1). Among the plant parts used as antidotes, leaves are most frequently used representing $46 \%$ followed by rhizomes/roots $(23 \%)$, bark, inflorescence and whole plant representing $8 \%$ each and fruit and petiole representing $4 \%$ each (Figure 2). The different forms of crude drug like paste, juice, infusion, crushed plant parts or acrid juice from the plants are administered externally or sometimes consumed orally to neutralize the venom. The most common form is application as paste which is recorded for 11 species followed by use as juice (6 species), infusion ( 3 species), crushed ( 2 species), acrid juice (1 species) and consumed (1 species). All the reported plant species are enumerated below with their botanical name, family, local name, voucher number, habit and local distribution with their occurrence i.e. wild/cultivated, $\mathrm{part} / \mathrm{s}$ used and their mode of uses.

Achyranthes bidentata Blume [Amaranthaceae]; Vangvat-tur

Exsiccate: Hmuifang, 03.06.2016, Malsawmi, 000612 (MZUH)

Habit \& Local Distribution: Wild annual herb, common in open vegetation and along the roadsides.

Part/s used: Leaves

Mode of uses: Extract of $10-15$ leaves is applied $1-2$ times to sores and wounds made by leech and bee stings.

Adiantum caudatum L. [Pteridaceae]; Chakawkria

Exsiccate: Sairang, 22.03.2018, Malsawmi, 000645 (MZUH)

Habit \& Local Distribution: Trailing fern, wild, common in moist regions on rocks.

Part/s used: Fronds

Mode of uses: Paste prepared from 5 - 7 fronds is applied against insect and scorpion bites.

Amomum dealbatum Roxb. [Zingiberaceae]; Aidu

Exsiccate: Sialsuk, 26.04.2017, Malsawmi 000625 (MZUH)

Habit \& Local distribution: Perennial rhizomatous herb, wild, occur in moist forest.

Part/s used: Young inflorescence

Mode of uses: Paste of $1-2$ young inflorescences is applied on areas of bee stings.

Butea superba Roxb. [Fabaceae]; Hruichun

Exsiccate: Hmuifang, 07.04.2018, Malsawmi, 000652 (MZUH)

Habit \& Local distribution: Woody climber, wild, found scattered in forests.

Part/s used: Roots, leaves

Mode of uses: Infusion of roots and crushed leaves applied against snakebites.

Chromolaena odorata (L.) R.M.King \& H.Rob. [Asteraceae]; Tlangsam

Exsiccate: Tanhril, 14.02.2018, Malsawmi 000641 (MZUH)

Habit \& Local distribution: An invasive exotic shrub, wild, abundant in wastelands.

Part/s used: Leaves

Mode of uses: About $3-5$ crushed leaves are applied on wound caused by leech as well as areas of insect bites.

Colocasia esculenta (L.) Schott [Araceae]; Dawl

Exsiccate: Tuirial, 07.06.2016, Malsawmi 000615 (MZUH)

Habit \& Local distribution: Herb, cultivated, commonly grown for its edible rhizomes.

Part/s used: Petiole

Mode of uses: Acrid juice of petiole is applied to wounds and against bee stings. 
Curcuma longa L. [Zingiberaceae]; Aeing

Exsiccate: Sialsuk, 24.05.2016, Malsawmi 000611 (MZUH)

Habit \& Local distribution: Rhizomatous herb, cultivated as a spice crop (turmeric).

Part/s used: Rhizome

Mode of uses: Crushed rhizomes is applied on insect bitten areas.

Elsholtzia griffithii Hook.f. [Lamiaceae]; Lengser

Exsiccate: Sairang, 29.08.2016, Malsawmi 000616 (MZUH)

Habit \& Local distribution: Culinary herb, cultivated for its aromatic leaves and inflorescence.

Part/s used: Leaves

Mode of uses: Paste of 6-10 crushed leaves is applied on insect bitten areas.

Eryngium foetidum L. [Apiaceae]; Bahkhawr

Exsiccate: Sairang, 22.03.2018, Malsawmi 000648 (MZUH)

Habit \& Local distribution: Perennial culinary herb, semi-cultivated.

Part/s used: Whole plant

Mode of uses: Whole plants including roots are consumed to treat snakebites.

Erythrina variegata L. [Leguminosae: Faboideae]; Fartuah

Exsiccate: Tanhril, 05.03.2017, Malsawmi 000618 (MZUH)

Part/s used: Bark

Habit \& Local distribution: Common wild tree, found scattered in most part of the state.

Part/s used: Stem bark

Mode of uses: Stem barks are crushed into paste and applied against snake bites.

Ficus prostrata (Wall. ex Miq.) Buch.-Ham. ex Miq. [Moraceae]; Thei-it

Exsiccate: Tuirial, 11.08.2017, Malsawmi 000627 (MZUH)

Habit \& Local distribution: Small tree, wild, less common in the state.

Part/s used: Root

Mode of uses: The paste prepared from fresh roots is applied against snake bitten areas.

Hedychium spicatum Sm. [Zingiberaceae]; Aithur

Exsiccate: Hmuifang, 02.08.2017, Malsawmi 000626 (MZUH)

Habit \& Local distribution: Perennial rhizomatous herb, wild, found in patches in wet and moist forests.

Part/s used: Rhizome

Mode of uses: Paste of rhizome is applied as an antidote against snakebites.

Mesua ferrea L. [Calophyllaceae]; Herhse

Exsiccate: Hmuifang, 16.02.2018, Malsawmi 000642 (MZUH)

Habit \& Local distribution: Evergreen tree, wild, common in the forests.

Part used: Leaves

Mode of uses: Paste of 1 - 2 leaves is applied on areas of bee and scorpion sting and snakebites.

Mikania micrantha Kunth [Asteraceae]; Japan-hlo

Exsiccate: Tanhril, 01.10.2016, Malsawmi 000617 (MZUH)

Habit \& Local distribution: Invasive climber, wild, abundant in wastelands and roadsides. Part/s used: Leaves

Mode of uses: Juice extracted from 5 - 10 leaves is applied $2-3$ times externally on insect bitten areas.

Mimosa pudica L. [Leguminosae : Mimosoideae]; Hlonaur

Exsiccate: Tanhril, 08.03.2017, Malsawmi 000619 (MZUH) 
Habit \& Local distribution: Perennial creeper, wild, common.

Part/s use: Whole plant

Mode of uses: Juice of whole plant is applied $2-3$ times on spider and scorpion bitten areas.

Mussaenda roxburghii Hook.f. [Rubiaceae]; Vakep

Exsiccate: Tanhril, 22.04.2017, Malsawmi 000623 (MZUH)

Habit \& Local distribution: Large shrub, wild, commonly found along the sides of hills.

Part/s used: Roots and leaves

Mode of uses: Juice of roots and leaves is applied 3 - 4 times on scorpion bitten areas.

Nicotiana tabacum L. [Solanaceae]; Vaihlo

Exsiccate: Hmuifang, 16.02.2018, Malsawmi 000643 (MZUH)

Habit \& Local distribution: Annual herb; cultivated, commonly grown as source of tobacco.

Part/s used: Leaves

Mode of uses: Infusion of $8-10$ leaves is applied $1-2$ times on insect bitten and leach wound areas.

Ocimum tenuiflorum L. [Lamiaceae]; Tulsi

Exsiccate: Sairang, 04.01.2018, Malsawmi 000629 (MZUH)

Habit \& Local distribution: Perennial aromatic sub-shrub, cultivated, grown for its medicinal value.

Part/s used: Roots

Mode of uses: A paste prepared from fresh roots is applied on insect bitten and leech wound areas.

Schima wallichii Choisy [Theaceae]; Khiang

Exsiccate: Tanhril, 29.12.2017, Malsawmi 000628 (MZUH)

Habit \& Local distribution: Tree, wild, frequently found in the state.

Part/s used: Fruits, peels and barks

Mode of uses: Juice prepared from fruits and peel is applied $2-3$ times on sting-wounds caused by bees, spiders and scorpions. The paste prepared from barks is applied against snake bitten areas.

Scoparia dulcis L. [Plantaginaceae]; Perhpawng chaw

Exsiccate: Tanhril, 04.01.2018, Malsawmi 000631 (MZUH)

Habit \& Local distribution: Annual herb, wild, commonly seen at roadsides and open forests. Part/s used: Whole plant

Mode of uses: Infusion prepared from 4-5 whole plant is applied locally against snake bites.

Sesamum indicum L. [Pedaliaceae]; Chhawhchhi

Exsiccate: Tuirial, 02.04.2017, Malsawmi 000621 (MZUH)

Habit \& Local distribution: Annual herb, cultivated, commonly grown for its edible seeds. Part/s used: Leaves

Mode of uses: Juice prepared from 3 - 5 leaves is applied 2-3 times on bee-sting wounds.

Tabernaemontana divaricata (L.) R.Br. ex Roem. \& Schult. [Apocynaceae]; Keltebengbeh

Exsiccate: Tuirial, 25.01.2018, Malsawmi 000632 (MZUH)

Habit \& Local distribution: Perennial shrub, semi-cultivated, not common in occurrence. Part/s used: Leaves, flowers

Mode of uses: Paste of leaves and flowers is applied on insect and scorpion bitten areas.

Zanthoxylum oxyphyllum Edgew. [Rutaceae]; Ching-it 
Exsiccate: Hmuifang, 11.05.2018, Malsawmi 000659 (MZUH)

Habit \& Local distribution: Common tree, often planted in home-gardens for its edible leaves and young shoots.

Part/s used: Leaves

Mode of uses: Paste of $8-10$ matured leaflets is applied on areas of ant and bee bitten areas.

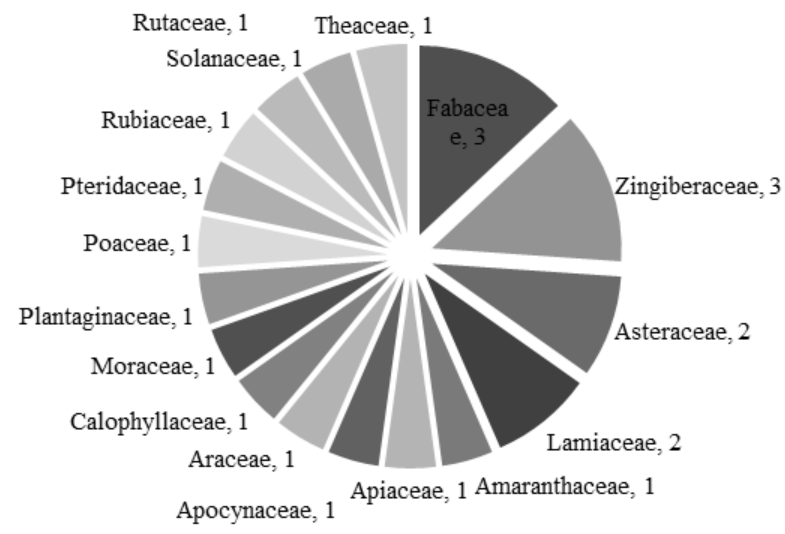

Figure 1. Distribution of families for plants used as antidote against animal bites in Mizoram

The present study is an attempt to recognize the rich traditional knowledge of the indigenous people of Mizoram regarding the herbal cure against venoms injected through animal bites. Due to difficult topography of the state, animal bites by venomous animal is a common problem for the inhabitants. These people have great understanding of their surrounding and learnt to get the remedy from natural sources including plants. Most of the plants reported in the present study were found to have many medicinal properties other

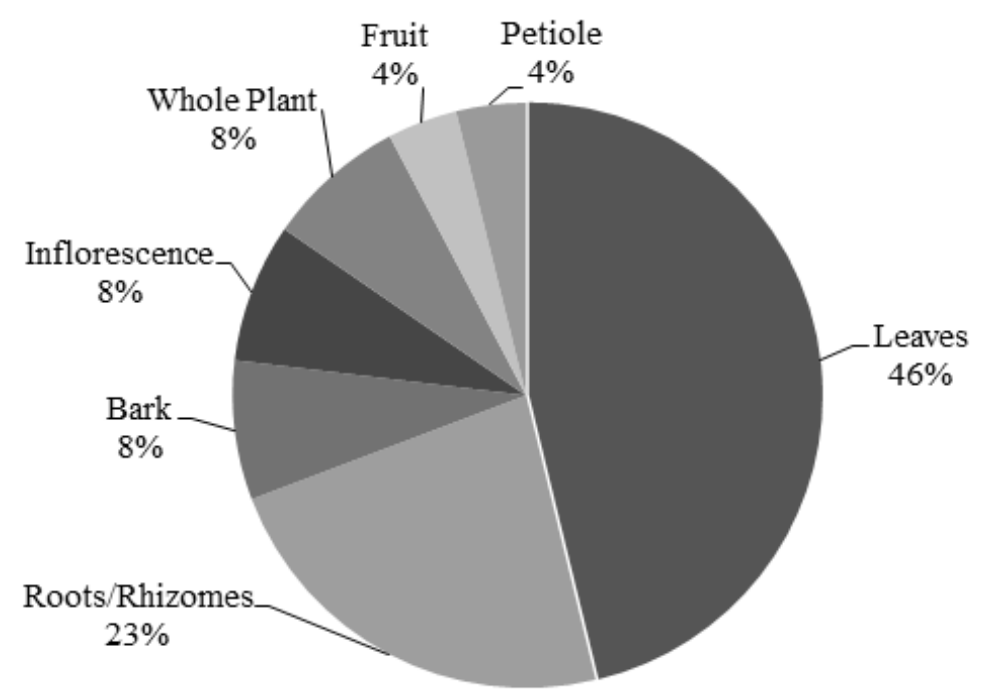

Figure 2. Different plant parts used as antidote against animal bites in Mizoram 
than the present use. As compared with various literatures related to the present study, it is noted that $30.43 \%$ of the plants are newly reported for their use while the remaining ones were mentioned in various ethnobotanical works from various parts of the world including Mizoram. The reports on the use of some plants like Achyranthes bidentata, Erythrina variegata, Ficus prostrata, Hedychium spicatum, Mesua ferrea, Mikania micrantha, and Schima wallichii were already reported from Mizoram (Lalfakzuala et al. 2007; Rai \& Lalramnghinglova 2010). The plants which are reported for first time against the bites of venomous animals include Adiantum caudatum, Amomum dealbatum, Butea superba, Chromolaena odorata, Elsholtzia griffithii, Mussaenda roxburghii and Zanthoxylum oxyphyllum. So, identification of bio-active components responsible for their anti-venomous potential can be tested on these prospective plants by conducting laboratory and field based studies for their efficacy and safety for formulation of commercial antidotes for near future.

\section{CONCLUSION}

The indigenous people of Mizoram have diverse knowledge on various uses of plants around them ranging from food, shelter, clothing to medicine, healthcare and protection from unwanted pests or enemies including venomous animal or insect bites. Many areas in Mizoram state comes under the semi-urbanized or remote region, and therefore remains under privileged in terms of medicine and healthcare infrastructure. One of the most common problem encountered relating to healthcare is emergency arising from venomous animal bites and its timely treatment. With many loopholes due to lack of medical facility, the intervention of locally available antidotes derived from plants based on traditional knowledge often proved as one of the most preferred technique to combat venomous animal/ insect bites. Most of the plants reported in the present study are commonly available ones and can be assessed easily at the time of emergency. This traditional knowledge has been passed from generations orally by their ancestors and is time tested after years long hit and trial indigenous methods. Proper documentation and further scientific research on the plants having potential activity as antidotes will able to mitigate the problems arising from scarcity of antidote medications mainly in remote region.

\section{Acknowledgements}

The authors are thankful to the local informants of Mizoram for sharing the valuable information and their help during collection of the voucher specimens during the survey.

\section{LITERATURE CITED}

Ali, A.N.M.I. \& Das, I. 2003. Tribal situation in North East India. Studies on Tribes and Tribals. 1 (2): $141-148$.

Deb, D.B. \& Dutta, R.M. 1987. A contribution to the flora of Mizoram. J. Econ. Taxon. Bot. 10 (1): $21-61$.

Espino-Solis, G.P.; Riaño-Umbarila, L.; Becerril, B. \& Possani, L.D. 2009. Antidotes against venomous animals: State of the art and prospective. J. Proteomics 72: $183-199$.

Fischer, C.E.C. 1938. The flora of Lushai hills. Rec. Bot. Surv. India 12(2): 75 - 161.

FSI 2017. India State of Forest Report, Forest Cover. Forest Survey of India, Dehra Dun, India

Gage, A.T. 1901. A Botanical tour in the South Lushai hills. Rec. Bot. Surv. India 1: 331 -369 . 
Jain, S.K. \& Rao, R.R. 1977. A handbook of Field and Herbarium Methods. Today \& Tomorrow's Printers \& Publishers, New Delhi.

Lalfakzuala, R.; Lalramnghinglova, H. \& Kayang, H. 2007. Ethnobotanical usages of plants in Western Mizoram. Indian J. Trad. Knowl. 6(3): 486 - 493.

Mahalik, P.R. \& Mahapatra, R.K. 2010. Documenting Indigenous Traditional Knowledge in Orissa. Orissa Review. May - June: 99 - 103.

Rai, P.K. \& Lalramnghinglova, H. 2010. Lesser known ethnomedicinal plants of Mizoram, North East India: An Indo-Burma hotspot region. J. Med. Pl. Res., 4(13): 1301 1307.

Sawmliana, M. 2013. The book of Mizoram Plants. Published by P. Zakhuma, Chandmari West, Aizawl.

Shil, S.; Dutta Choudhury, M. \& Das, S. 2014. Indigenous knowledge of medicinal plants used by the Reang tribe of Tripura state of India. J. Ethnopharm. 152: $135-141$.

Singh, N.P.; Singh, K.P. \& Singh, D.K. 2002. Flora of Mizoram, Vol. - 1 (Ranunculaceae Asteraceae). Botanical Survey of India, Kolkata.

Sinha, G.P.; Singh, D.K. \& Singh, K.P. 2012. Flora of Mizoram. Vol.-II (CampanulaceaeSalicaceae), Botanical Survey of India, Kolkata.

Vetter, R.S. \& Visscher, P.K. 1998. Bites and stings of medically important venomous arthropods. Intn. J. Dermatol. 37: 481 - 496. 